\title{
New Hope to Urbanism: Congruence of Architectural Conservation, Urban Design and Sustainability
}

\author{
Divya Chakravarti \\ Conservation Architect
}

\begin{abstract}
In countries like India and China and others in South Asia and Europe, where the roots of history is so inter twined in the urban fabric it is close to impossible to segregate the principles of conservation from that of urban design or urban planning. It is truly beneficial to the city, people, and the future development as well, if the cultural and historic context of the urban core is only altered upon rather than being completely stripped to the bare bone and replaced in its entirety. It is high time we (architects, urban planners and the general public) realize that context matters and that new buildings and additions to old buildings should be harmonious with their neighbours. It is important to place value on all aspects of the built environment, including architectural styles, urban fabric, the decorative arts, cultural purposes, etc [1]. The question that needs to be addressed: "With contemporary design being redefined by architects, and urbanists who are recovering the historic language associated with traditional architecture and the city, how can preservation change its focus or update its mission?"
\end{abstract}

Keywords: Conservation; Urban Planning; Sustainability

\section{Introduction}

The principles and concept of architectural conservation is misunderstood in many cases and misused in some others. Looking at modernism as a movement which has been in relevance for a few decades now, it cannot be completely deemed "unfit for conservation".[2] Architectural conservation is beyond preserving classical, gothic, colonial styles of architecture. In the days when green architecture and sustainability ishot topic of the hour, we cannot ignore the fact that the greenest building is the one that is already in existence, (although would require some percentage of retrofitting) embodied energy plays a crucial role in understanding the importance of historic buildings and their purpose in today's context.

Most research focuses on the sustainability of new buildings with respect to materials, building technology and other tangible factors. I would like to propose adding the third prong to the fork - the concept of conservation, with sustainability and urban design can go a long way in designing, planning and maintaining clean, healthy and relevant cities pertaining to certain regions, people, cultures, etc. thereby adding the realm of certain intangible factorslike historic and cultural relevance to people in the city/town.

\section{Literature Survey}

As a conservation architect, I am often faced with two issues at the beginning of any project. The primary issue is facing the reluctance of the client and the inertia from their end to do the best for the building. However old or important the building, the main selling point is the economics behind it: the eternal question- "What will I profit out of this endeavour?" The second issue I come across is - "Do I look at the building as an individual structure or part of a heritage district or precinct?"
To answer these two questions we need to move away from mere emotional and historical value and move onto a more tangible terrain where I can confidently assign numbers- in terms of making money, saving energy and thereby assigning a sense of pride towards the structure. Urban conservation is the other side of the coin to architectural conservation- the principle remain the same it is the change only in the stakeholders and it is no monger in the interest of one individual rather in the interest of a much larger audience- could be a town, or a city or even of national importance.

\section{The Issue}

It is important to not lose sight of big picture - the overall historic fabric of which each building is an important part. Even if the project entails only a single historic structure it is the duty of the conservation architect to step it up and realize the impact the building would have on entire historic district. If not we will end up having disjointed buildings put together to come up with distorted historic fabriccompletely altered and unredeemable.

\section{Causes}

\section{1) Apathy towards heritage structures:}

In India, our send of pride towards our history and heritage is relatively low and is dormant unless provoked. We take pride in our technological and scientific advancements, which is important too but not with the same passion we should be able to look back at our history. This lack of pride is reflected in our attitude towards our heritage structures. The government of a developing country like India, during the process of fund allocation, conservation/ preservation definitely takes a back seat when poverty, unemployment, food shortage and many such major issues are there. As a very small percentage of heritage structures in the country come under private ownership, we lose chunks of undocumented history by mere apathy alone. 


\section{International Journal of Science and Research (IJSR) \\ ISSN (Online): 2319-7064}

Index Copernicus Value (2015): 78.96 | Impact Factor (2015): 6.391

2) Conservation is treated like an elite subject

For conservation to work and function at a basic level it is important to incorporate it with planning policies of every city. The age of the city is immaterial to the fact that conservation is required as apart of policy planning. The attitude that conservation is meant only for colonial, gothic and classical buildings should be altered and we must accept that it goes beyond merely the style of architecture. It is crucial to ensure conservation is incorporated at a grass root level- while making planning policies besides the planners, engineers, developers, politicians; it is essential that architects, especially conservation architects are also included in the panel. It is high time that conservation/ preservation are treated like mainstream and not niche or elitist.

\section{3) No incentives for conservation in the private sector}

The builds that reflect our history and heritage are not always majestic building along the coast; there are also treasure troves in small lanes and streets where residences have prevailed from 150 years or so.Buildings are important for different reasons- it could be the architecture, sometimes it is the history, and sometimes it is the context. [3] These too cannot be ignored, but owners cannot be forced to conserve them when they are financially unstable or unable to do so. In such cases, it is crucial that the owners are provided some relief from the government in the form of perks to make sure they keep their houses rather than demolishing them or selling them to developers.

\section{4) The lack of understanding of the term urban conservation}

More often than not, architectural conservation and urban conservation are treated like synonyms, which definitely is not the right attitude to project. Though the basic principles might be the similar, the cause and effect are vastly different so it is important that urban conservation is understood for what it is rather than exist as a mere shadow of architectural conservation.

Historical urban areas are part of the history and memory of a city, and history would be incomplete without them. They are excellent sources of information on the style of a city and the basic elements of urban landscape. Any lone building in these areas may not be qualified for special protection, and hence they are often ignored. However, when buildings are seen together as a wholesome historic fabric, they constitute a landscape that displays the typical scene of a city in a certain historical period, reflecting a particular style of architecture or context to the city which gives them a higher value. [4]

\section{Urban Conservation across the globe}

In 1967, England issued the Civic Amenity Act, which clearly states that urban areas with unique historic values and architectural features should be protected, considering their "collective value." [5] This also includes all external spaces, roads and even certain old trees that should be protected. The Civic Amenity Act specifies that buildings within the historical urban areas should not be dismantled, and the reconstruction and renovation of these buildings are only allowed with registered plans in detail for which permission must be asked from a panel of experts within the community. Thus, development projects are discouraged in these areas.

In October 1987, the International Council on Monuments and Sites (ICOMOS) approved the Washington Charter for protecting the ancient urban center of a city and similar other historical landscapes. According to this charter, the spatial layout and the relationship between the block (series of buildings within the space of 250 feet $\times 1000$ feet) and its environment must be given special attention. The Washington Charter also emphasizes the functions and roles of the blocks in history. This charter differs from the Venice Charter, which focuses on the protection of cultural relics.

The Washington Charter requires the active participation of the residents in historical urban areas and for the improvement in the infrastructure in local areas. Moreover, it is important that residential conditions should be improved, and the protection must be made part of the agenda both for theeconomic and social development of the town. [6]

The legal protection of historical urban areas in China originated in 1986. The State Council declared the list of the second batch of historical and cultural cities. In this document, blocks with historical or local features, building complex, towns, and villages are required to be protected, and the local government should declare these areas as "historical and cultural protected areas." This practice was reinforced by the formulation of the Law on Protection of Cultural Relics in 2002, although in this updated version, the historical blocks, building complex, towns, and villages are redefined as historical urban areas, historical villages, and historical towns, respectively. [7]

The protection of historical urban areas should be focused on the historical landscape. The protection of historical urban areas is different from that of cultural relic units, which stipulates that cultural relics should be preserved in the original condition. Additionally, the elements of a historical landscape, including roads, lanes, yard walls, banks, and trees, should be protected, which is different from the protection of cultural relic units. Finally, the continuity in function and cultural succession should be protected. Historical urban areas are home to a huge number of residents, and these areas are the living form of cultural relics. Aside from the buildings themselves, the culture attached to them should be protected as well. The normal social life and the cultural diversity should be preserved and conserved, respectively. Moreover, the living environment and the local economy must be improved and promoted, is similar to the protection of historical and cultural cities. [8]

\section{Typical Problems with the Protection of Historical Urban Areas}

1) In some areas, the government themselves have mandated commercial enterprises to dismantle all the houses and replace them with high-rises to solve the problems of poor houses and inadequate infrastructure. The protection of historical urban areas has been misinterpreted as city transformation, resulting in the destruction of historical 


\section{International Journal of Science and Research (IJSR) \\ ISSN (Online): 2319-7064}

Index Copernicus Value (2015): 78.96 | Impact Factor (2015): 6.391

urban areas. Urban renewal is one of the most misinterpreted terms where refurbishment of urban fabric is considered the same as demolition and rebuilding.[9]

2) In some places, the real historical urban areas are being replaced with fake ones. Moreover, the real historical blocks are being dismantled for the sake of commercial expansion. As a result, many historical urban areas with enormous value have become worthless replicas of old streets- they are not even mere shadows of the past.

3) In some areas, developers realize that land value and commercial potential are very important. The functions of these areas have changed completely, gentrifying historic urban areas into niche/ elite markets. The switch from dwelling areas to bars and catering and from general shopping streets to luxury shopping areas though not very sudden, it does create a dramatic change in the urban scape. Original residents have moved away, and enterprises have been attracted, thereby losing the original context of the place. As a result of these changes, the environment has been ruined for temporary commercial benefits. The truth has been replaced with a mere mask and local features with changing fads. These historical urban areas no longer remind the people of the past. The construction of reproductions of old streets due to tourism or commercial motivations is totally different from the protection of historical urban areas.

4) In many areas, a dense population is considered as a barrier to the protection; therefore, many people have been moved out of their homes; not only rendering them homeless or rootless but also erasing the context of the place with respect to its people, making it an empty shell rather than a thriving urban space.

\section{Adopting Proper Methods for Protecting Historical Urban Areas}

Historical urban areas are crucial elements in the protection of heritage and culture of a city. Their protection does not only involve just planning, but also a comprehensive understanding of heritage and its preservation. The methods and policies for the protection of historical urban areas should be given special attention.

In historical urban areas, it is not just the physical structures that are important but also the culture and cultural diversity in these areas should be protected as well such that their functions are not be undermined, yet the living environment should improve, which is essential for the protection of historical urban areas. The protection of historical urban areas includes

- Protecting the exterior appearance- both aesthetically as well as structurally

- Transforming the interior to meet the needs of the modern people, and

- Improving local infrastructure and environment by taking gradual steps.

In this process, the local government body should play a leading role and involve the participation of local residents to ensure public ownership to ensure safe and optimum usage of the spaces. The protection of historical urban areas should not be confused with real estate development, and the profits of investments should not be the primary concern. [10]

In past decade or so, there have been successful models of historical urban area protection, and they have the following points in common.

- The traditional landscape, as well as the functions and culture, are well preserved.

- The gradual and mild steps taken avoid possible conflicts in the community, which facilitates the succession of the culture, meets the real requirement of the local residents, and at the same time reduces the burden of the government.

- The quintessential cooperation between the government and its citizens produces a favourable result, in which the government is responsible for improving infrastructure and the environment, and the residents are responsible for improving their own living conditions. Thus, the heritage and culture are preserved, and the environment and living standards of the local residents are improved.

\section{Sustainability as a Measure to Promote Conservation}

The benefits of reusing a historic and existing building versus those of constructing new buildings are frequently discussed in terms of economic, cultural and design values. If those discussions are expanded to include environmental impact and sustainability then one must also address the concept of embodied energy.

Embodied energy is the total of all the energy that is utilized to extract, process, deliver and install the materials needed to construct a building. Embodied energy is a concept rarely discussed in the realm of sustainable design tough the concept of operation-energy reduction is widely spoken about. Besides the community of sustainable architects and researchers, the conservation architect should also benefit from exploring the depth of embodied energy and their calculations as this could be used as a definite and a more quantitative method of measuring overall environmental benefits of renovating/ retrofitting a historic building versus demolition and new construction. [11]

Embodied energy definitely deserves a place in the equation of sustainable design, especially when discussing historic preservation. The existing historic built environment represents a huge resource that can be conserved and made efficient use of in $21^{\text {st }}$ century especially as we are close to fossil fuel exhaustion. More research is required in this field as in the current day the complete demolition and disposal of a historic building and the "trapped" embodied energy that it represents is not measured at all by any of the current rating systems. A better and holistic rating system is required so that conservation architect can use it as a strong basis for saving an important piece of heritage. A mere amalgamation of conservation principles and the concept of embodied energy will lead to an emphatic argument for environmental and economic benefits of architectural conservation of heritage structures. [12] 


\section{International Journal of Science and Research (IJSR) \\ ISSN (Online): 2319-7064}

Index Copernicus Value (2015): 78.96 | Impact Factor (2015): 6.391

\section{Conclusions}

On the whole, there is a consensus that sustainability and conservation are both compatible and complimentary, although there remains a continued lack of balanced, holistic approach to guiding development and moving towards sustainability. The absence of the social and cultural perspective is evident in the conservation and heritage planning literature in which the physical product forms the principal focus. Practical problems do arise from the dichotomous relationship between preservation for posterity and change and development necessary for keeping heritage places alive and attractive- bringing in the importance of planning principles of various cities. [13]

\section{Future Scope}

This paper has examined the potential relationship amongst three crucial factors: sustainability, conservation and urban design; which help develop a holistic approach to urbanism and planning. Four objectives may be identified: 1) need for standardisation of quantities like embodied energy that is suitable to our Indian scenario- which will aid any conservation architect in creating holistic reports on historic buildings or urban areas. 2) The need to protect our cultural heritage, yet at the same time in a manner that provides a certain purpose to the community and comfort to its inhabitants. 3) The acceptance of change and development to ensure continuity and sustained development 4) quintessential to realize that conservation is not a single stream of thought that can be applied to a building alone but also an entire urban core which requires a multi- faceted approach.

\section{References}

[1] Semes, Steven. The Future of the Past: a conservation ethic for architecture, urbanism, and historic preservation. WW Norton and Company, 2009. Chapter 1,Page24

[2] Ibid; Page 70

[3] Eclectic Revisited: Preserving Venice's Architectural Context, Mimi Zeiger, and May13, 2014; Retrieved on $4^{\text {th }}$ July 2017.

[4] Frontiers of Architectural Research, Volume 1, Issue 1, March 2012, Problems and solutions in the protection of historical urban area, JinghuiWang

[5] Ibid, Page 42

[6] Ibid, Page 43

[7] Law on Protection of Cultural Relics (2007)

The Law on Protection of Cultural Relics of the People's Republic of China was adopted at the 31st Session of the Standing Committee of the 10th National People's Congress of the People's Republic of China on December 29, 2007 and has come into force as of the date of promulgation.

[8] Law on Protection of Cultural Relics (2007)

The Law on Protection of Cultural Relics of the People's Republic of China was adopted at the 31st Session of the Standing Committee of the 10th National People's Congress of the People's Republic of China on
December 29, 2007 and has come into force as of the date of promulgation.

[9] Code of Conservation Planning for Historic Cities (2005)The Code of Conservation Planning for Historic Cities (GB50357-2005) was issued by Proclamation No. 358 of the Ministry of Construction of the People's Republic of China and has come into force as of 2005.

[10] Frontiers of Architectural Research, Volume 1, Issue 1, March 2012, Problems and solutions in the protection of historical urban area, JinghuiWang

[11]Booz, Allen\&Hamilton, Inc. Energy Conservation Assessing the Benefits Of Historic Preservation: Methods and Washington, D.C.: Historic Preservation, Examples. Advisory Council on 1979

[12] Embodied Energy and Historic Preservation : A Needed Assessment ; Mike Jackson, APT Bulletin, Vol 36, No.4( 2005) Pg 47-52; Accessed 4 ${ }^{\text {th }}$ April 2017

[13] Bridging Architectural Conservation and Sustainability; INTACH Journal of Heritage Studies, Vol 1 ; Divya Chakravarti; Pg 43 